\title{
Population pharmacokinetic analysis and dosing regimen optimization of penicillin $G$ in patients with infective endocarditis
}

Toshiaki Komatsu, Takayuki Inomata², Ichiro Watanabe², Masahiro Kobayashi', Hideya Kokubun ${ }^{1}$, Junya Ako² and Koichiro Atsuda ${ }^{1}$

\begin{abstract}
Background: This study was designed to evaluate the population pharmacokinetics (popPK) of penicillin $G$ in patients with infective endocarditis and establish a dosage regimen based on pharmacokinetic data and clinical outcome.

Method: Forty-six serum penicillin G samples from 25 individuals were analyzed using a nonlinear mixed-effects model. popPK were estimated using a one-compartment model. We created a receiver operating characteristic (ROC) curve for penicillin G efficacy and the ratio of its minimum concentration ( $\mathrm{Cmin}$ )/minimum inhibitory concentration (MIC). Simulations were used to optimize the penicillin $\mathrm{G}$ dosage regimen using this ratio.

Result: Estimated popPK were: $\mathrm{CL}(\mathrm{L} / \mathrm{h})=0.21 \times$ creatinine clearance $(\mathrm{CLCr})(\mathrm{mL} / \mathrm{min}), \mathrm{Vd}(\mathrm{L})=28$.9. The areas under the ROC curves were 0.87 for clinical efficacy. The cut-off value of penicillin G Cmin/MIC was 60 . The continuous administration of 1 million IU penicillin $\mathrm{G} / \mathrm{h}$ was necessary to achieve a positive outcome for patients with normal renal function (CLCr $\geq 60 \mathrm{~mL} / \mathrm{min}$ ).
\end{abstract}

Conclusion: Our findings suggest that population-based parameters are useful for evaluating penicillin $\mathrm{G}$ pharmacokinetics and that an individualized dosage should be determined based on a described dosage regimen.

Keywords: Penicillin G, Population pharmacokinetics, Dosing optimization, Nonlinear mixed-effects model

\section{Background}

Penicillin G, discovered by Alexander Fleming in 1928, was the first antibiotic to be recognized. Penicillin $G$ is still used widely for the treatment of meningitis, dermatomyositis, and infective endocarditis caused by viridans group streptococci. Nevertheless, infective endocarditis remains a disease with high morbidity and with a mortality rate of $16-37.1 \%$ [1-3]. The 2009 European Society of Cardiology guidelines recommend 4 weeks of monotherapy with penicillin $\mathrm{G}$ or ceftriaxone for infective endocarditis caused by susceptible streptococci [4]. The efficacy of penicillin G correlates with the percentage of time above the minimum inhibitory concentration (MIC) (TAM). In general, the therapeutic goal

\footnotetext{
* Correspondence: t.komatu@kitasato-u.ac.jp

'Department of Pharmacy, Kitasato University Hospital, 1-15-1 Kitasato,

Minami-Ku, Sagamihara, Kanagawa 252-0375, Japan

Full list of author information is available at the end of the article
}

for curing infections caused by gram-positive organisms is an antimicrobial TAM of at least $30 \%$ [5]. At a normal penicillin G dosage of 4 million international units (IU) administered intravenously every $4 \mathrm{~h}$, a TAM of at least $30 \%$ has been reported to result in $100 \%$ penicillin-susceptible (penicillin $\mathrm{MIC} \leq 0.125 \mathrm{mg} / \mathrm{L}$ ) or intermediate penicillinresistant streptococci (MIC $0.125-2 \mathrm{mg} / \mathrm{L}$ ). Therefore, we do not believe this parameter is achievable for infective endocarditis [6]. In general, the population pharmacokinetics (popPK) of penicillin $G$ are insufficiently known. Thus, the popPK of penicillin G were analyzed in patients with infective endocarditis. We also determined the relationship between the blood concentrations of penicillin $G$ and clinical outcomes. Furthermore, effective initial dosing regimens for infective endocarditis were determined according to our popPK data. 
Table 1 Patient characteristics

\begin{tabular}{ll}
\hline Number of Patients & 25 \\
\hline Gender (Male:Female) & $16: 9$ \\
Age (year) & $54 \pm 17^{\mathrm{a}}(21-83)^{\mathrm{b}}$ \\
$\mathrm{Scr}(\mathrm{mg} / \mathrm{dL})$ & $0.92 \pm 0.56(0.51-3.26)$ \\
$\mathrm{CLcr}(\mathrm{mL} / \mathrm{min})$ & $82.52 \pm 33.29(11-144)$ \\
ALT $(\mathrm{IU} / \mathrm{L})$ & $26.80 \pm 26.45(4-106)$ \\
Weight $(\mathrm{kg})$ & $55.35 \pm 33.31(33-86.9)$ \\
Observation & 46 \\
PCG concentraion $(\mu \mathrm{g} / \mathrm{mL})$ & $33.2 \pm 45.2(0.5-212.3)$ \\
\hline
\end{tabular}

Scr serum creatinine, $C L c r$ creatinine clearance, $A L T$ alanine aminotransferase ${ }^{\mathrm{a}}$ Mean \pm standerd diviation

${ }^{\mathrm{b}}$ Range

\section{Methods}

\section{Data source}

Clinical data were collected from patients treated with penicillin G potassium (Meiji Seika Pharma Co. Ltd, Tokyo, Japan) for suspected or documented infective endocarditis at Kitasato University Hospital between January 1997 and April 2013. The collected data included age, gender, height, body weight (BW), alanine aminotransferase (ALT), serum creatinine, creatinine clearance (CLcr), isolated microorganisms, clinical outcome, and serum concentrations of penicillin G. CLcr was estimated from the serum creatinine level by the Cockcroft-Gault method [7]. Failure of penicillin $G$ treatment was defined as persistence of fever and/or bacteremia by the causative pathogen requiring a change in antibiotic therapy, and infection-related mortality within 30 days.

Table 2 Causative microorganisms

\begin{tabular}{|c|c|c|c|}
\hline & Total & $\begin{array}{l}\text { Penicillin } \\
\text { success }\end{array}$ & $\begin{array}{l}\text { Penicillin } \\
\text { failure }\end{array}$ \\
\hline & $n=21$ & $n=15$ & $n=6$ \\
\hline Size of vegetation (mm) & $11.7 \pm 6.0$ & $12.3 \pm 6.3$ & $9.8 \pm 5.7$ \\
\hline PCG MIC & $0.11 \pm 0.20$ & $0.07 \pm 0.02$ & $0.21 \pm 0.38$ \\
\hline $\begin{array}{l}\text { PCG trough serum } \\
\text { concentrations }(\mu \mathrm{g} / \mathrm{mL})\end{array}$ & $7.8 \pm 9.0$ & $10.1 \pm 9.8$ & $2.2 \pm 1.2$ \\
\hline $\begin{array}{l}\text { Viridans group streptococci } \\
\text { species level not determined }\end{array}$ & 4 & 1 & 3 \\
\hline streptococcus sanguis & 5 & 2 & 3 \\
\hline streptococcus gordonii & 4 & 4 & 0 \\
\hline streptococcus agalactiae & 2 & 2 & 0 \\
\hline streptococcusmutans & 1 & 1 & 0 \\
\hline streptococcus intermedius & 2 & 2 & 0 \\
\hline streptococcus mitis & 1 & 1 & 0 \\
\hline streptococcus oralis & 1 & 1 & 0 \\
\hline streptococcus constellatus & 1 & 1 & 0 \\
\hline
\end{tabular}

Blood samples were obtained from a brachial vein immediately before and 2 or $3 \mathrm{~h}$ after administration of penicillin $G$ for determination of serum penicillin $G$ levels. Human subject procedures were approved by the Ethics Committee of Kitasato University Hospital. In addition, we obtained written informed consent from each patient.

\section{Assay of penicillin G concentrations}

Blood samples were collected using serum-separator tubes, centrifuged immediately at $3000 \mathrm{rpm}$ for $10 \mathrm{~min}$ at room temperature and the serum separated. Penicillin $G$ concentrations were measured using minor modifications of a high-performance liquid chromatography (HP LC) method published previously [8]. The mobile phase consisted of acetonitrile and $50 \mathrm{mM}$ potassium phosphate buffer $(1: 1, \mathrm{v} / \mathrm{v})$, adjusted to $\mathrm{pH} 5.0$ at a flow rate of $0.8 \mathrm{~mL} / \mathrm{min}$. Methanol $(500 \mu \mathrm{L})$ was added to $200 \mu \mathrm{L}$ of serum. This mixture was vortexed immediately for $30 \mathrm{~s}$ and finally centrifuged at 15,000 rpm for $5 \mathrm{~min}$ at room temperature. The supernatant was filtered and $20 \mu \mathrm{L}$ injected into the HPLC. The lower limit of detection of penicillin $\mathrm{G}$ was $0.5 \mu \mathrm{g} / \mathrm{mL}$. The coefficients of variation for both intra- and inter-assay precision were less than $10 \%$.

\section{Pharmacokinetic calculations}

Data analyses were performed with the nonlinear mixed effects model program (version VI, level 1.0) developed by Beal and Sheiner [9]. A one-compartment pharmacokinetic model was employed using the ADVAN1 and TRANS2 subroutines. The parameters of the structural model were clearance (CL) and volume of distribution (Vd). The first order conditional estimation method was applied for modeling. Inter-individual variability of the parameters was best explained by an exponential error model $(\mathrm{Pi}=\mathrm{TV}(\mathrm{Pi}) \times \exp (\eta \mathrm{i}))$ where $\mathrm{Pi}$ indicated an individual value, $\mathrm{TV}(\mathrm{Pi})$ was the population value for the parameters described in the equation, and $\eta \mathrm{i}$ was the random deviation of $\mathrm{Pi}$ from $\mathrm{TV}(\mathrm{Pi})$. The value of $\eta \mathrm{i}$ was assumed to be independent and distributed normally with a mean of 0 and a variance of $\omega^{2}$. The residual (intra-individual) variability of the parameters was also explained by a proportional error model $($ Cobs, ij $=$ Cpred,ij $\times(1+\varepsilon \mathrm{ij}))$ where Cobs,ij and Cpred,ij denote the $j^{\text {th }}$ observed and predicted concentrations for the $\mathrm{i}^{\text {th }}$ subject, respectively, and $\varepsilon$ is a random intraindividual error that is distributed normally with a mean of 0 and variance $\sigma^{2}$.

\section{Covariate analysis}

Covariance of the following variables was tested to improve the popPK model: age, serum creatinine, CLcr, $\mathrm{BW}, \mathrm{ALT}$, and gender. The influence of continuous 


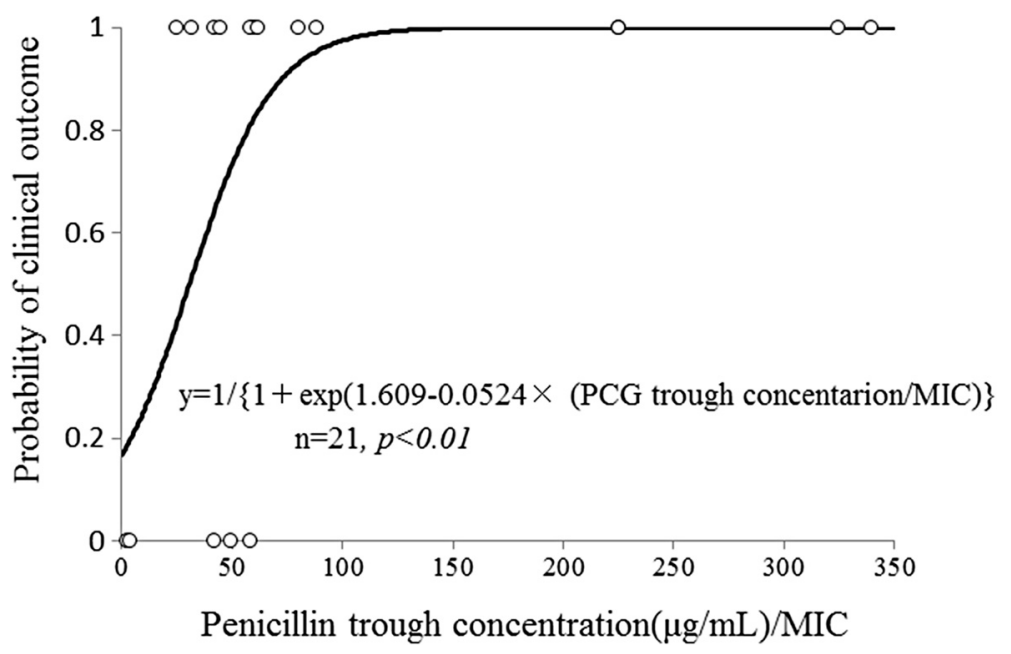

Fig. 1 Penicillin G minimum serum concentrations/MIC and logistic regression model for clinical outcomes (failure, 0; success, 1)

covariates on the pharmacokinetic parameter $\mathrm{TV}(\mathrm{P})$ was modeled according to the following equations: TV $(\mathrm{P})=\theta \mathrm{p}+\theta \mathrm{c} \times($ covariance $)$, and $\mathrm{TV}(\mathrm{P})=\theta \mathrm{p} \times \theta \mathrm{c}^{\text {(covariance })}$. Covariance showing a correlation with the pharmacokinetic parameters was introduced into the model. The significance of the influence of covariates was evaluated by a change of -2 log likelihood (the minimum value of the objective function: OBJ). An OBJ decrease of more than 6.63 from the full model $\left(X^{2}\right.$ : degree of freedom $=1, P<0.01$ ) was considered statistically significant during the forward inclusion process. The full model was structured by incorporating the significant covariates, and the final model was developed by a

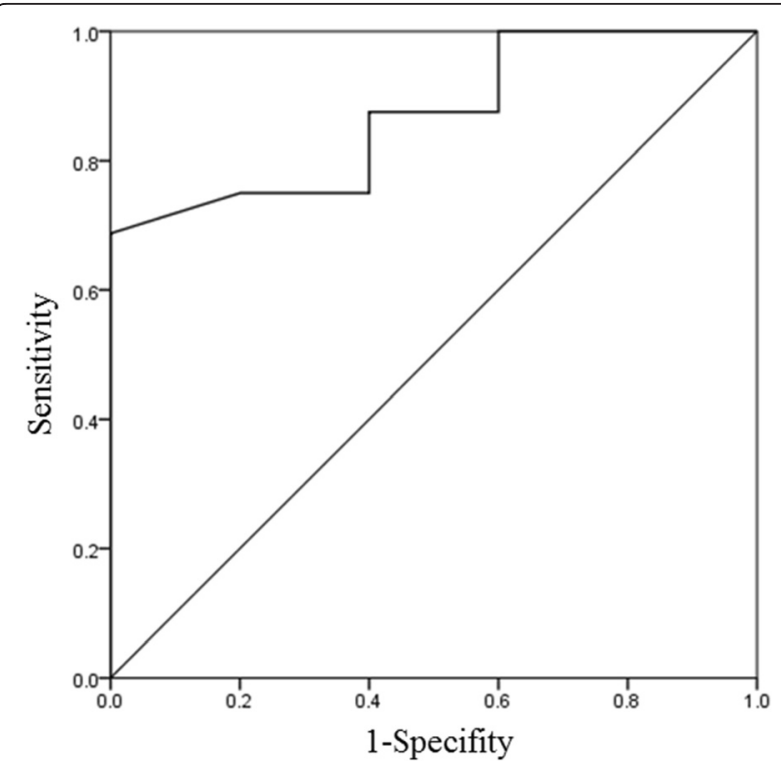

Fig. 2 Receiver operating characteristic curve for predicting clinical efficacy using penicillin G minimum serum concentration/MIC backward elimination method. When one covariate factor was excluded from the full model, an OBJ that increased more than 6.63 from the full model was considered statistically significant.

\section{Model evaluation}

The adequacy of fitting was examined by plotting the predicted versus the observed concentration of penicillin $\mathrm{G}$, the individual predicted concentration after each Bayesian step versus observed concentration, and the conditional weighted residual concentration versus the predicted one. The accuracy and robustness of the final model were assessed using the bootstrap method [10]. Bootstrap samples were generated by repeated random sampling of the original data set. The size of each bootstrap sample was the same as that of the original sample. Two hundred bootstrap samples were constructed, and the final model was determined by testing these samples repeatedly. The mean parameter estimates obtained from

Table 3 Hypothesis testing for fixed effect model on penicillin G pharmacokinetics

\begin{tabular}{llll}
\hline Fixed model & OBJ & -2 .II.d & $p$-value \\
\hline $\mathrm{CL}=\theta 1$ & 356.307 & & \\
$\theta 1+\theta 2 \times \mathrm{CLCr}$ & 239.004 & 117.303 & $<0.001$ \\
$\theta 1+\theta 2 \times 1 / \mathrm{sCr}$ & 280.388 & 75.919 & $<0.001$ \\
$\theta 1+\theta 2 \times \mathrm{BW}$ & 323.407 & 32.9 & $<0.001$ \\
$\theta 1 \times \theta 2^{\text {ALT }}(\mathrm{ALT}>40=0, \mathrm{ALT}<40=1)$ & 337.037 & 19.27 & $<0.001$ \\
$\theta 1 \times \theta 2^{\text {sex }}($ Male $=1$, Female $=0)$ & 324.973 & 31.334 & $<0.001$ \\
$\theta 1 \times \theta 2^{\text {Age }}($ Age $>65=1$, Age $<64=0)$ & 347.699 & 8.608 & $<0.005$ \\
$V d=\theta 3$ & & & \\
$\theta 3+\theta 4 \times$ BW & 356.307 & 0 & N.S. \\
\hline
\end{tabular}

N.S not significant, $C L C r$ creatinine clearance, $A L T$ alanine aminotransferase, $B W$ body weight 
Table 4 Summary of results for the basic and final population models

\begin{tabular}{|c|c|c|c|c|}
\hline & \multirow{2}{*}{\multicolumn{2}{|c|}{$\begin{array}{l}\text { Basic model } \\
C L(L / h)=\theta 1\end{array}$}} & \multicolumn{2}{|c|}{ Final model } \\
\hline & & & \multicolumn{2}{|c|}{$\begin{array}{l}C L(L / h)=\theta 1 \times \\
C L C r(m L / m i n)\end{array}$} \\
\hline & \multicolumn{2}{|c|}{$\mathrm{Vd}(\mathrm{L})=\theta 2$} & \multicolumn{2}{|c|}{$\mathrm{Vd}(\mathrm{L})=\theta 2$} \\
\hline Parameter & Mean & $95 \% \mathrm{Cl}$ & Mean & $95 \% \mathrm{Cl}$ \\
\hline$\theta 1$ & 8.09 & $6.75-9.42$ & 0.21 & $0.173-0.246$ \\
\hline$\theta 2$ & 39.1 & $34.0-44.2$ & 28.9 & $24.0-33.7$ \\
\hline
\end{tabular}

Interindividual variability

$\begin{array}{lllll}\eta_{C L} & 0.765 & 0.465-1.065 & 0.0835 & 0.0292-0.137 \\ \eta v d & 0.217 & 0.135-0.298 & 0.104 & 0.094-0.115\end{array}$

Residual variability

$\begin{array}{lllll}\varepsilon & 0.0643 & 0.0306-0.0979 & 0.0304 & 0.0269-0.0334\end{array}$

$\eta$, random variable, which is normally distributed with mean 0 and variance $\omega 2$

$\varepsilon$, random error, which is normally distributed with mean 0 and variance $\sigma^{2}$ $\mathrm{Cl}$ confidence interval, $\mathrm{CLCr}$ creatinine clearance

the replicates using normal calculations were compared with those obtained from the original data set.

Target serum concentration of penicillin $\mathrm{G}$ in patients with infective endocarditis

The relationship between the penicillin $\mathrm{G} \mathrm{Cmin/}$ MIC ratio and clinical outcome (clinical failure $=0$, clinical success $=1$ ) was analyzed using a logistic regression model. Statistical analyses were performed using JMP statistical software (version 6.03; SAS Institute, Cary, NC, USA). Additionally, receiver operating characteristic (ROC) curve analysis was performed to
Table 5 Final population pharmacokinetic parameters of penicillin $\mathrm{G}$

\begin{tabular}{|c|c|c|c|}
\hline Parameter & Estimate & $\begin{array}{l}\text { RSE (covariance } \\
\text { step) }\end{array}$ & $\begin{array}{l}95 \% \mathrm{Cl} \text { (bootstrap } \\
\text { method) }\end{array}$ \\
\hline \multicolumn{4}{|c|}{ Population mean } \\
\hline \multicolumn{4}{|c|}{$\begin{array}{l}\mathrm{CL}(\mathrm{L} / \mathrm{h})=\theta 1 \times \mathrm{CLCr} \\
(\mathrm{mL} / \mathrm{min})\end{array}$} \\
\hline$\theta 1$ & 0.21 & $8.81 \%$ & $0.171-0.249$ \\
\hline \multicolumn{4}{|l|}{$\mathrm{Vd}(\mathrm{L})=\theta 2$} \\
\hline$\theta 2$ & 28.9 & $8.58 \%$ & $23.4-34.7$ \\
\hline \multicolumn{4}{|c|}{$\begin{array}{l}\text { Interindividual } \\
\text { variability }\end{array}$} \\
\hline$\eta_{C L}$ & 0.0835 & $33.1 \%$ & $0.0171-0.1397$ \\
\hline ฤvd & 0.104 & $5.22 \%$ & $0.0087-0.1203$ \\
\hline \multicolumn{4}{|c|}{ Residual variability } \\
\hline$\varepsilon$ & 0.0304 & $5.85 \%$ & $0.0265-0.0342$ \\
\hline
\end{tabular}

determine the efficacy of a test by providing information about both sensitivity and specificity at different cut-off points. A two-tailed $\mathrm{P}$ value of less than 0.05 was considered significant. The MIC of penicillin G was determined using the MicroScan WalkAway 96 plus (Beckman Coulter, Brea, CA, USA) fully automatic bacterial system that conforms to the micro dilution method according to the Clinical and Laboratory Standards Institute.
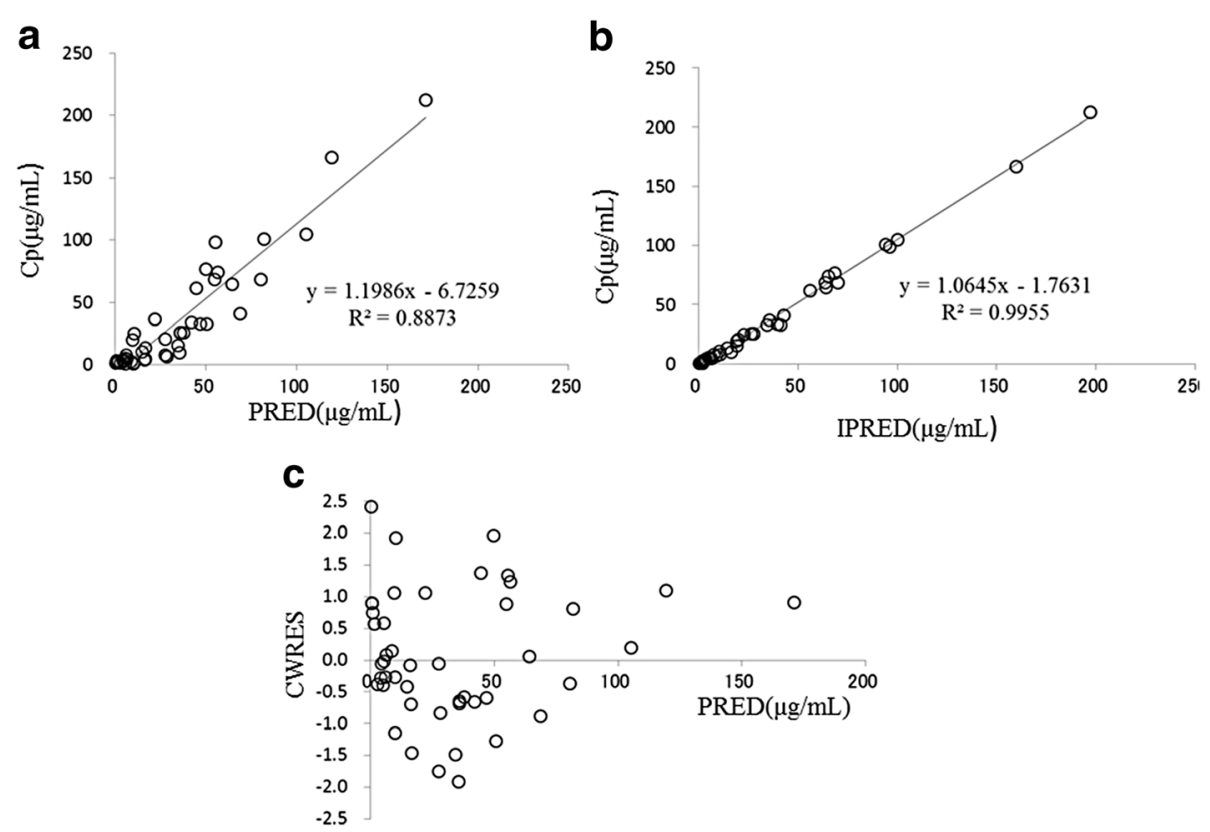

Fig. 3 Relationship between observed penicillin serum concentrations (Cp) and predicted concentrations (PRED) (a), or individual predicted concentrations after Bayesian fitting (IPRED) (b). Scatter plot of conditional weighted residuals (CWRES) versus predicted PRED is presented in (c) 

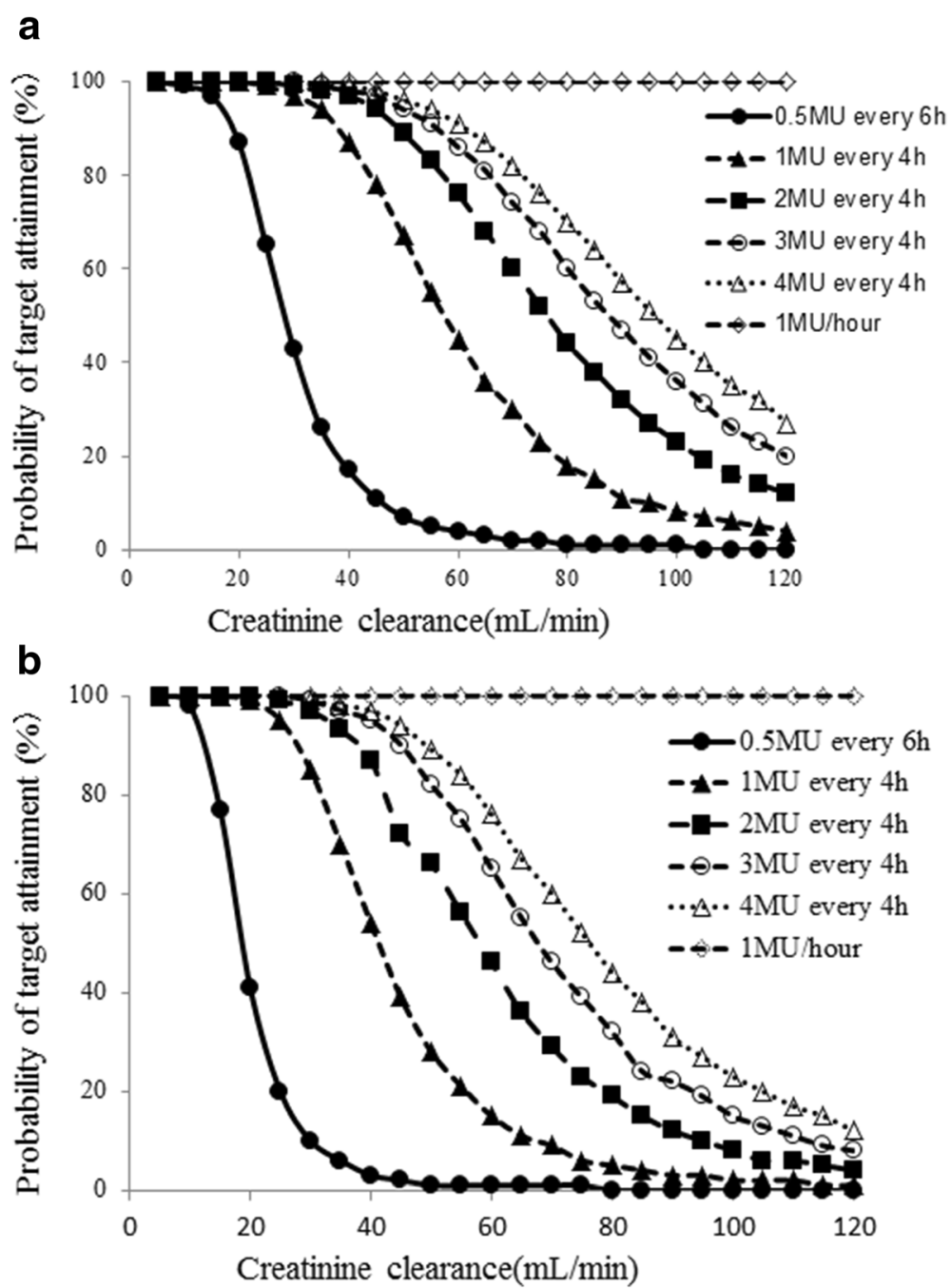

Fig. 4 Probability of attaining targets above a penicillin minimum serum concentration/MIC ratio of 60 at CLCr ranging from 5 to 120 with MIC fixed at (a) 0.06 or (b) $0.12 \mu \mathrm{g} / \mathrm{mL}$

\section{Determination of the dosing regimen}

Pharmacokinetic simulations were performed to determine the optimal dosing regimen based on our popPK data. Penicillin G concentrations were simulated for 1000 patients using the final popPK model. For the assessment of efficacy, the percentage of patients that achieved penicillin $\mathrm{G} \mathrm{Cmin} / \mathrm{MIC}$ ratios above 60 was calculated for each data set. For the assessment of safety, the percentage of patients that achieved penicillin $G$ peak concentrations below $100 \mu \mathrm{g} / \mathrm{mL}$ was calculated for each data set. The MIC was fixed at 0.06 and $0.12 \mathrm{mg} / \mathrm{L}$ because these MICs are seen frequently in our hospital. Monte Carlo simulation was performed using Crystal Ball 2000 software (Oracle, Redwood Shores, CA, USA).

\section{Results}

Patient characteristics are shown in Table 1. Serum concentrations of penicillin $G$ were measured in a total of
25 patients treated with penicillin $\mathrm{G}$ for infective endocarditis. Viridans group streptococci were isolated in 21 of these patients, 15 of whom showed a positive response to penicillin G (success) and 6 showed no response (failure) (Table 2).

Figure 1 shows the relationship between penicillin $G$ $\mathrm{Cmin} / \mathrm{MIC}$ and clinical outcome (failure $=0$, success $=$ 1). Penicillin G Cmin/MIC was a significant predictor of the following clinical outcome equation: probability of a positive clinical outcome $=1 /\{1+\exp (1.609-0.0524 \times<$ penicillin $\mathrm{G}$ Cmin/MIC $>$ )\}. Figure 2 shows the optimal ROC curve for predicting clinical efficacy using the penicillin $\mathrm{G}$ Cmin/MIC ratio. The area under the ROC curve was 0.83 and the cut-off value of penicillin $G$ Cmin/MIC for clinical efficacy was 60 (sensitivity $68 \%$, specificity $100 \%$ ).

The results from each covariate model are shown in Table 3. CLcr, serum creatinine, BW, ALT, gender, and 


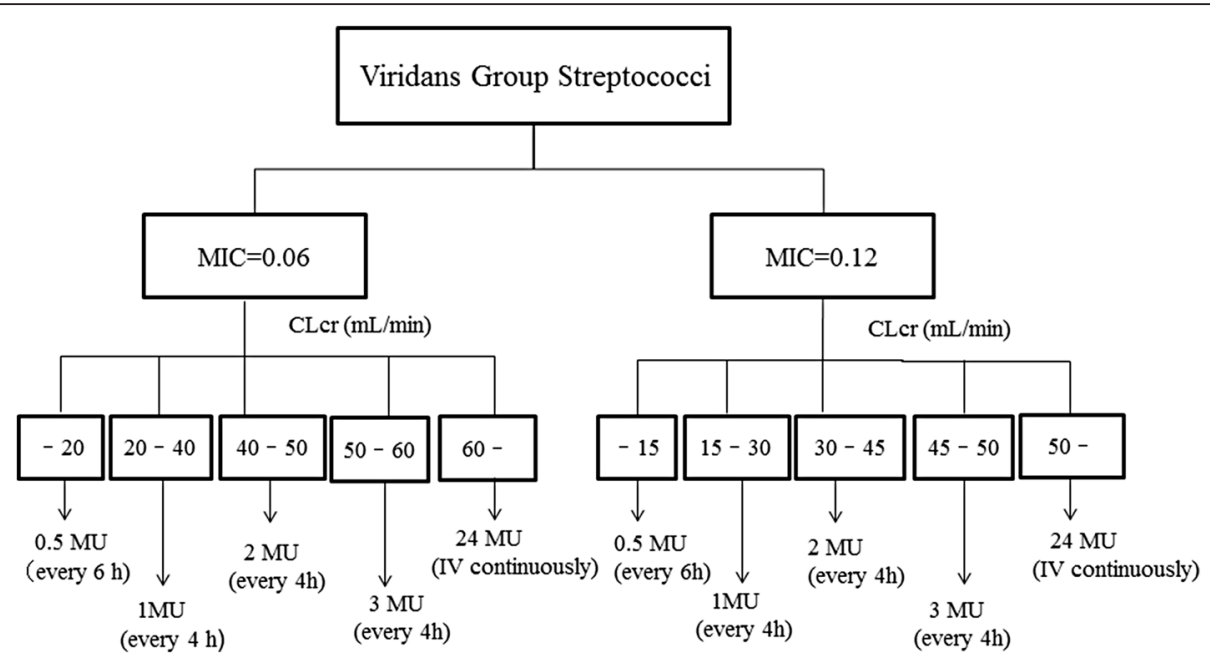

Fig. 5 Nomogram for the initial dosage of penicillin against viridans group streptococci

age were significant covariates for the CL of penicillin G. During backward deletion from the full model, CLcr remained in the model and caused a significant increase in the OBJ. Table 4 summarizes the popPK estimates from the basic and final models. The final model was: $\mathrm{CL}(\mathrm{L} / \mathrm{h})=0.21 \times \mathrm{CLcr}(\mathrm{mL} / \mathrm{min}), \mathrm{Vd}(\mathrm{L})=28.9$. The coefficients of variation of the inter-individual variability $\left(\omega^{2}\right)$ of $\mathrm{CL}, \mathrm{Vd}$, and the residual variability $\left(\sigma^{2}\right)$ were $28.8,32.4$, and $17.4 \%$, respectively.

Assessment of the predictive performance of the final model is presented in scatter plots of the observed versus the population-predicted concentrations (Fig. 3a), and the individual-predicted concentrations of penicillin G (Fig. 3b). Conditional weighted-residual concentration versus the population predicted concentration is presented in Fig. 3c. These plots are distributed symmetrically around the line of identity, indicating that the model describes the serum concentration of penicillin $G$ adequately.

In the bootstrap analysis of the final model, 158 of 200 bootstraps showed successful results. The values of the parameters used in the final model generated from the bootstrap analysis were similar to those of the developed model (Table 5).

A simulation was performed using the final model to determine the optimal dosing regimen in patients with renal impairment. Penicillin G concentrations were simulated for 1000 patients exhibiting CLcr ranging from 5 to $120 \mathrm{~mL} / \mathrm{min}$. The target was a $\mathrm{Cmin} / \mathrm{MIC}$ value above 60 as estimated by Fig. 2. The simulation was performed for dosages ranging from 0.5 million IU every $6 \mathrm{~h}$ to 4 million IU every $4 \mathrm{~h}$, as well as 1 million IU/h (Fig. 4). Figure 5 shows the typical initial dose of penicillin $G$ for MICs of 0.06 and $0.12 \mu \mathrm{g} / \mathrm{mL}$ in patients with various CLcr based on the simulation experiments.

\section{Discussion}

This is the first popPK study of penicillin $G$ that was used to propose a dosing regimen. Although a threecompartment model has been described for penicillin $G$ [11], we used a one-compartment model because our sampling points for serum penicillin $G$ levels were at the trough and 2 or $3 \mathrm{~h}$ after administration of penicillin $\mathrm{G}$, and there were few data during the elimination phase. As a result, CLcr was a significant covariant for the systemic clearance of penicillin $G$ that occurs through the kidney $[12,13]$. Dittert et al. reported that the $\mathrm{Vd}$ for penicillin $\mathrm{G}$ was $33 \mathrm{~L}$ in healthy people [13]. This value is very close to that obtained in our study $(28.9 \mathrm{~L})$. The reported serum half-life of penicillin $\mathrm{G}$ in patients with normal renal function ranged from 0.38 to $0.78 \mathrm{~h}$ [14, 15]. These values are very similar to our data $(0.79 \mathrm{~h})$ calculated by keeping the CLcr fixed at $120 \mathrm{~mL} / \mathrm{min}$.

Predictions of the penicillin $\mathrm{G}$ concentrations were made with the final regression model. The model exhibited a good linear correlation between observations and the individual predicted concentrations after the Bayesian steps. The final model lacked bias on the relationship between Figs. 3a, b. Specifically, the conditional weighted residuals were acceptable to within three standard deviations, which is generally recognized as the criterion for no selection biases (Fig. 3c). Therefore, we concluded that the final model had a good predictive performance.

The logistic regression model (Fig. 1) and ROC curve (Fig. 2) revealed a significant association between penicillin $\mathrm{G} \mathrm{Cmin/MIC} \mathrm{ratios} \mathrm{and} \mathrm{the} \mathrm{therapeutic} \mathrm{effect.} \mathrm{The}$ threshold penicillin G Cmin/MIC ratio that led to clinical success was above 60, the cut-off associated with $100 \%$ probability of response to therapy. Figure 4 also 
showed the probability of success with a penicillin $G$ Cmin/MIC ratio above 60 and a penicillin G peak concentration below $100 \mu \mathrm{g} / \mathrm{mL}$. At this peak concentration, patients became comatose with continuous muscle jerking [16]. García-Cabrera et al. reported infective endocarditis with a mortality rate of $30 \%$ [17]. Our data showed a $29 \%$ failure rate of penicillin G treatment (6/21). Although there were some patients with a positive response to penicillin $\mathrm{G}$ whose penicillin $\mathrm{G}$ Cmin/MIC ratios were lower than 60 , patients whose values were over 60 all had a positive response.

This regimen was used to determine the typical initial dosage of penicillin $\mathrm{G}$ against viridans group streptococci in patients with various CLcr. The continuous administration of 1 million IU/h at a MIC of 0.06 was necessary to achieve therapeutic success against infective endocarditis in patients with normal renal function (CLcr $>60 \mathrm{~mL} / \mathrm{min}$ ). Continuous infusion of penicillin $\mathrm{G}$ is recommended by the American Heart Association guidelines [18]. Overall, the method described in this project assured therapeutic efficacy in infective endocarditis with a negligible risk of neurotoxicity [19]. The initial dosage regimen determined using our model will be useful for patients with infective endocarditis caused by Streptococcus spp. A prospective study using this regimen will help determine the robustness and reliability of our model.

\section{Conclusion}

This is the first popPK study of penicillin G that was used to propose a dosing regimen. CLcr was a significant covariant for the systemic clearance of penicillin G. Additionally, the results showed that continuous administration of 24 million units of penicillin $G$ over $24 \mathrm{~h}$ was necessary to achieve a positive outcome for patients with normal renal function (CLcr $\geq 60$ ). Our findings suggest that population-based parameters are useful for evaluating penicillin $G$ pharmacokinetics and that an individualized dosage should be determined based on a described dosage regimen.

\section{Abbreviations \\ ALT: alanine aminotransferase; BW: body weight; CLcr: serum creatinine, creatinine clearance; Cmin: minimum concentration; HPLC: high-performance liquid chromatography; MIC: minimum inhibitory concentration; OBJ: objective function; popPK: population pharmacokinetics; ROC: receiver operating characteristic; TAM: time above the minimum.}

\section{Competing interests}

The authors declare that they have no competing interests.

\section{Authors' contributions}

TK wrote the manuscript. TK, IW, TI, HK, JA, and KA designed the study. TK and MK analyzed data. All authors read and approved the final manuscript.

\section{Acknowledgments}

We thank Kazuo Yago, Ph.D, for his support in performing this study. We would like to thank all staff members of Kitasato University Hospital that were involved in this study.

\section{Author details}

'Department of Pharmacy, Kitasato University Hospital, 1-15-1 Kitasato, Minami-Ku, Sagamihara, Kanagawa 252-0375, Japan. ${ }^{2}$ Department of Cardiovascular Medicine, Kitasato University School of Medicine, Sagamihara, Japan.

Received: 24 January 2016 Accepted: 15 March 2016

Published online: 05 April 2016

\section{References}

1. Tuğcu A, Yildirimtürk O, Baytaroğlu C, Kurtoğlu H, Köse O, Sener M, et al Clinical spectrum, presentation, and risk factors for mortality in infective endocarditis: a review of 68 cases at a tertiary care center in Turkey. Turk Kardiyol Dern Ars. 2009:37:9-18.

2. Tawfiq JA, Sufi I. Infective endocarditis at a hospital in Saudi Arabia: epidemiology, bacterial pathogens and outcome. Ann Saudi Med. 2009:29:433-6.

3. Hoen B, Alla F, Selton-Suty C, Béguinot I, Bouvet A, Briançon S, et al. Changing profile of infective endocarditis: results of a 1-year survey in France. JAMA. 2002;288:75-81.

4. Habib G, Hoen B, Tornos P, Thuny F, Prendergast B, Vilacosta I, et al. Guidelines on the prevention, diagnosis, and treatment of infective endocarditis (new version 2009): the Task Force on the Prevention, Diagnosis, and Treatment of Infective Endocarditis of the European Society of Cardiology (ESC). Eur Heart J. 2009;30:2369-413.

5. Craig WA. Pharmacokinetic pharmacodynamic parameters: rationale for antibacterial dosing of mice and men. Clin Infect Dis. 1998;26:1-10.

6. Weinstein MP, Klugman KP, Jones RN. Rationale for revised penicillin susceptibility breakpoints versus Streptococcus pneumoniae: coping with antimicrobial susceptibility in an era of resistance. Clin Infect Dis. 2009;48:1596-600

7. Cockcroft DW, Gault MH. Prediction of creatinine clearance from serum creatinine. Nephron. 1976;16:31-41.

8. Muller AE, DeJongh J, Bult Y, Goessens WH, Mouton JW, Danhof M, et al. Pharmacokinetics of penicillin $\mathrm{G}$ in infants with a gestational age of less than 32 weeks. Antimicrob Agents Chemother. 2007;51:3720-5.

9. Beal SL. NONMEM user's guides. San Francisco: NONMEM Project Group, University of California; 1992.

10. Ette El. Stability and performance of a population pharmacokinetic model. J Clin Pharmacol. 1997;37:486-95.

11. Ebert SC, Leggett J, Vogelman B, Craig WA. Evidence for a slow elimination phase for penicillin G. J Infect Dis. 1988;158:200-2.

12. Holland SM, Livesey EF, Owen J, Pennington GW, Roberts JB, Somers GF. Blood and urine levels following intramuscular administration of potassium penicillin V. Antibiot Chemother. 1960;10:25-9.

13. Dittert LW, Griffen Jr WO, LaPiana JC, Shainfeld FJ, Doluisio JT. Pharmacokinetic interpretation of penicillin levels in serum and urine after intravenous administration. Antimicrob Agents Chemother. 1969;9:42-8.

14. Kampmann J, Hansen JM, Siersboek-Nielsen K, Laursen H. Effect of some drugs on penicillin half-life in blood. Clin Pharmacol Ther. 1972; 13:516-9.

15. Kunin CM. Serum binding, distribution and excretion of four penicillin analogues following intravenous injection in man. Proc Soc Exp Biol Med. 1961;107:337-41.

16. Wickerts CJ, Asaba H, Gunnarsson B, Bygdeman S, Bergstrom J. Combined carbon haemoperfusion and haemodialysis in treatment of penicillin intoxication. Br Med J. 1980;24:1254-5.

17. García-Cabrera E, Fernández-Hidalgo N, Almirante B, Ivanova-Georgieva $R$, Noureddine M, Plata A, et al. Neurological complications of infective endocarditis: risk factors, outcome, and impact of cardiac surgery: a multicenter observational study. Circulation. 2013;127:2272-84.

18. Baddour LM, Wilson WR, Bayer AS, Fowler Jr VG, Bolger AF, Levison ME, et al. Infective endocarditis: diagnosis, antimicrobial therapy, and management of complications: a statement for healthcare professionals from the Committee on Rheumatic Fever, Endocarditis, and Kawasaki 
Disease, Council on Cardiovascular Disease in the Young, and the Councils on Clinical Cardiology, Stroke, and Cardiovascular Surgery and Anesthesia, American Heart Association: endorsed by the Infectious Diseases Society of America. Circulation. 2005;111:394-434.

19. Bryan CS, Stone WJ. "Comparably massive" penicillin G therapy in renal failure. Ann Intern Med. 1975;82:189-95.

Submit your next manuscript to BioMed Central and we will help you at every step:

- We accept pre-submission inquiries

- Our selector tool helps you to find the most relevant journal

- We provide round the clock customer support

- Convenient online submission

- Thorough peer review

- Inclusion in PubMed and all major indexing services

- Maximum visibility for your research

Submit your manuscript at www.biomedcentral.com/submit 